\title{
Outdoor testing of the photoprotection provided by a new water-based broad-spectrum SPF50+ sunscreen product: two double-blind, split-face, randomized controlled studies in healthy adults
}

This article was published in the following Dove Press journal:

Clinical, Cosmetic and Investigational Dermatology

\author{
Corinne Granger' \\ Yolanda Sola ${ }^{2}$ \\ Yolanda Gilaberte ${ }^{3-6}$ \\ Carles Trullàs' \\ 'Innovation and Development, ISDIN, \\ Barcelona, Spain; ${ }^{2}$ Meteorology Group, \\ Department of Applied Physics, \\ University of Barcelona, 08028 Barcelona, \\ Spain; ${ }^{3}$ Dermatology Department, \\ Hospital Universitario Miguel Servet, \\ Zaragoza, Spain; ${ }^{4}$ Academia Española de \\ Dermatología y Venereología, Zaragoza, \\ Spain; ${ }^{5}$ Revista Actas Dermo-Sifiliogr \\ áficas, Zaragoza, Spain; ${ }^{6} \mathrm{Health}$ Sciences, \\ University of Zaragoza, Zaragoza, Spain
}

Correspondence: Corinne Granger ISDIN, Provençals 33, Barcelona 08019, Spain

Tel +34932402020

$\mathrm{Fax}+34932020980$

Email corinne.granger@isdin.com

\begin{abstract}
Purpose: Users often under-apply sunscreens, and one of the main reasons cited for this is the cosmetic formulation of the product. To address this, we developed a water-based sunscreen. The product underwent standard laboratory testing (ISO 24444: 2010) and was determined as sun protection factor (SPF) 50+. However, such laboratory testing does not take into account environmental factors of in-use conditions that could potentially affect sunscreen efficacy, particularly of new cosmetic formulations. We aimed to test this product in conditions more representative of real-life solar exposure, to confirm its reported laboratory efficacy.
\end{abstract}

Methods: Two double-blind, randomized, controlled, split-face intra-individual studies were conducted during summer months in Barcelona. One study compared the product against an SPF15 control (reference standard P3 of ISO 24444: 2010), while the other compared against an SPF50+ control (another commercially available sunscreen). A technician applied the products before sun exposure: investigational product (IP) to one half of the face and the respective control product to the other. Subjects spent 4-6 hrs outdoors performing quiet activities, and sunscreens were reapplied at 2 hourly intervals. A dermatologist clinically scored facial erythema at baseline and at $24 \mathrm{hrs}$.

Results: Sixty-five subjects were included in total. In both studies, skin treated with the IP showed no significant increase in clinical erythema scoring at $24 \mathrm{hrs}$. There were statistically significant differences between the IP and the SPF15, but not between the IP and the SPF50+ control. SPF15 did not protect all subjects against solar-induced erythema.

Conclusion: These outdoor studies confirm the efficacy of this new SPF50+ water-based sunscreen in conditions that closer represent real-life sun exposure.

Keywords: erythema, sunburn, sunscreen, photoprotection, real-life testing

\section{Introduction}

Solar radiation induces acute and chronic damage to the skin and is potentially carcinogenic. ${ }^{1,2}$ Despite efforts to increase awareness, ${ }^{3}$ sunburn prevalence remains high. A 2012 report by the Centre for Disease Control and Prevention found that $50 \%$ of adults and $66 \%$ of white adults aged 18-29 in the USA reported at least one sunburn in the previous 12 months. ${ }^{4}$ Ultraviolet (UV) B induces sunburn, and DNA may be damaged directly via UVB-induced generation of cyclobutane pyrimidine dimers and thymine dimers, or indirectly via UVA-induced generation of reactive 
oxygen species. ${ }^{2}$ Epidemiological evidence shows an association between cumulative sun exposure and nonmelanoma skin cancers, ${ }^{2}$ and between episodic severe sunburn and melanoma. ${ }^{5,6}$

Photoprotection is therefore recommended to minimize skin damage. ${ }^{7}$ Key approaches are seeking shade, wearing protective clothing, and using sunscreen on exposed areas. Sunscreens are often the main mode of protection used in outdoor activities, ${ }^{4,8}$ yet despite this reliance, many users continue to under-apply sunscreens at quantities below the recommended $2 \mathrm{mg} / \mathrm{cm}^{2} ., 10$ A reluctance to apply abundant sunscreen has been attributed to cosmetic aspects, such as oiliness, stickiness, or unpleasant texture. ${ }^{11,12}$ To address this, we developed a water-based broad-spectrum sunscreen product (ISDIN Fusion Water) formulated to absorb quickly and avoid residues, that would be pleasant to use while still providing very high UV protection.

This new product was tested using the international standard laboratory method (ISO 24444: 2010) ${ }^{13}$ and determined to have a sun protection factor (SPF) of $50+$. SPF is the well-established metric for sunscreen protection against sunburn, determined on in vivo laboratory testing. Although SPF has become the accepted worldwide standard for measuring sunscreen efficacy, there remain some controversies regarding the method and the effects of real conditions of use on the protection achieved in outdoor conditions. ${ }^{14,15}$ SPF testing aims to induce erythema as rapidly as possible ${ }^{13,16}$ using solar simulators that emit UV radiation in the region of $290-400 \mathrm{~nm}$, while added filters cut off radiation below $290 \mathrm{~nm}$ and beyond UV wavelengths; consequently, the effects of infrared or visible radiation on skin are not taken into account. ${ }^{2,17}$

Furthermore, in real-life conditions, the qualities of the product once applied to the skin may be influenced by the environment (eg, temperature). ${ }^{18,19}$ Unlike more wellstudied, classical oil-based products, there was no evidence on how this newly developed water-based product would behave in real life. Our aim was to assess the efficacy of this product in conditions that would closer represent real-life solar exposure, to provide a more robust level of evidence on its efficacy outside the laboratory, while still ensuring adequate application. Our hypothesis was that the investigational product (IP) would provide better protection than the SPF15 and comparable protection to the SPF50+ control, but we wanted to establish this in a non-laboratory setting, in case the new product behaved unpredictably in real-life conditions.

\section{Materials and methods}

\section{Study design}

Two double-blind, split-face, randomized controlled studies were designed to assess the clinical efficacy in preventing erythema of a new water-based broad-spectrum SPF50+ sunscreen product using established sunscreen products as controls. The studies were designed in parallel, but conducted in different months for logistical reasons, from July to September 2018, in Barcelona, Spain. They were designed as independent studies but used a similar methodology.

\section{IP and controls}

The IP was a combination of lipophilic organic sun filters: ethylhexyl methoxycinnamate, butyl methoxydibenzoylmethane, ethyl hexyl triazone, and a physical filter: titanium dioxide, formulated in a water-based innovative galenic formulation. The IP was compared in the two separate studies against an SPF15 sunscreen (reference standard P3 of ISO 24444: $2010,{ }^{13}$ containing the solar filters ethylhexyl methoxycinnamate, butyl methoxydibenzoylmethane and phenylbenzimidazole sulfonic acid) and a different SPF50+ sunscreen from the same manufacturer (solar filters: octocrylene, butyl methoxydibenzoylmethane, bis-ethylhexyloxyphenol methoxyphenyl triazine and titanium dioxide). The SPF50+ control was chosen in the absence of a reference standard for SPF50+ assessment.

\section{Subjects}

The inclusion criteria for the two studies were generally equivalent: healthy male and female adults aged 18-60 years old (18-55 in study 2), of all skin types, with Fitzpatrick phototype I-IV (I-III in study 2), ITA (individual typology angle) over 28 on the back, who were at least occasional users of cosmetic products or sun care products. The studies excluded those with skin marks that could interfere with assessment (pigmentation disorders, scarring, large number of nevi, etc.), history of allergic reactions to similar products, history of skin cancer or dysplastic nevi, active facial skin disease, endocrine disease, immunosuppressive conditions or medications, and any treatments (topical or oral, including food supplements) that may affect skin pigmentation or reactions. Pregnant or breastfeeding women were not allowed. Twenty-nine subjects were initially included in study 1 (vs SPF15), and 38 in study 2 (vs SPF50+). Study 1 compared against SPF15 and was conducted in 
September, and study 2 compared against SPF50+ and was conducted in July. As stated above, the two studies were designed in parallel, as independent studies involving similar methodology, and due to logistical reasons only were conducted in this order.

Both studies were performed on sunny days with clear skies or low cloud cover; if there was cloudy weather on the planned study day, the studies were postponed. Both were split-face design, with the IP applied to one hemiface and SPF15 or SPF50+ control to the other. The side of the face to be treated with each product was allocated according to a randomization table. The study technician applied $2 \mathrm{mg} / \mathrm{cm}^{2}$ of each product using a finger stall $30 \mathrm{mins}$ before exposure. In the first 4-5 subjects, a Wood lamp was used to assess even coverage with the sunscreen products after the first application.

Study 1 (vs SPF15) lasted 6 hrs (approximately 10.30 $\mathrm{am}-12.30 \mathrm{pm}$ and $1.30 \mathrm{pm}-5.30 \mathrm{pm}$, with a $30-\mathrm{min}$ break between) and was conducted on the sun terrace of a fitness center. Subjects performed free quiet activities (no waterrelated or excessive sweat-inducing activities were planned). Subjects were instructed to request reapplication of sunscreen products as they felt necessary, and the technician then applied them on their request, after the first $2 \mathrm{hrs}$.

Study 2 (vs SPF50+) was conducted in a public square over 4 hrs. A subgroup of four subjects began the study and conducted prescribed activities at 30-min intervals: walking, sitting (reading/listening to music), and lying face upward. They spent 2 hrs outdoors (10 am-12 noon) then sunscreen was reapplied during a 30-min indoor break, before a further 2 hrs' exposure (12.30-2 pm). However, the investigator judged that the period of exposure was too long during critical hours, so the protocol was modified for the remaining 25 subjects, to start and finish earlier in the day ( $9 \mathrm{am}-1 \mathrm{pm})$ with 5 min shade breaks upon request, and reapplication of sunscreen products upon subjects' request any time after the first $2 \mathrm{hrs}$. Subjects were also allowed to perform the permitted activities freely provided they respected the study constraints.

\section{Erythemal UVB radiation}

Cumulative doses of erythemal UVB radiation were determined from erythemal irradiances measured with a broadband YES UVB-1 pyranometer (Yankee Environmental Systems, MA, USA) installed on the roof of the faculty of physics of the University of Barcelona. The instrument belongs to the Radiometric Network of the Spanish Meteorological Service (AEMET). The pyranometer has a spectral response close to the erythema action spectrum ${ }^{20}$ and measures the solar radiation received by a horizontal surface from the whole sky. The UV index, ${ }^{21}$ a tool developed to inform the public of the potential erythemal effect of solar radiation, was determined from these measurements. Bech et $\mathrm{al}^{22}$ previously reported on the climatology and UV index in this location.

\section{Endpoints}

The objective of the study was to assess the efficacy of the IP in preventing erythema in a setting more representative of reallife solar exposure. The primary endpoint of both studies was the erythema score following outdoor sun exposure, based on clinical examination of facial erythema at baseline and at $20 \pm 4$ hrs postexposure. In study 1 (vs SPF15) a scale of 0-9 was used, with 0 being no erythema and 9 being very intense erythema, ${ }^{23}$ while study 2 used a scale of $0-4^{24,25}$ (Table 1).

Subjects were also questioned and examined by a dermatologist or responsible technician regarding local skin reactions at these same time points and given an individual observation sheet to record any symptoms. The dermatologists and technicians who assessed erythema, as well as the subjects, were blinded to the treatment allocations.

As a secondary objective, we were interested to see if the study design would discriminate between the photoprotective ability of our water-based IP and the control sunscreens.

\section{Statistical analysis}

Means and SD were calculated for clinical scoring. Wilcoxon signed rank test was used to compare the

Table I Clinical erythema scale

\begin{tabular}{|l|l|l|l|}
\hline \multicolumn{2}{|l|}{ Study I } & \multicolumn{2}{l|}{ Study 2} \\
\hline Score & Description & Score & Description \\
\hline 0 & No erythema & 0 & No erythema \\
1 & Very slight erythema (barely perceptible) & $1-2-3$ & Very slight erythema \\
2 & Slight erythema (well defined) & $4-5$ & Slight erythema \\
3 & Moderate erythema & $6-7$ & Moderate erythema \\
4 & Strong erythema & $8-9$ & Marked erythema \\
\hline
\end{tabular}


differences between the score at baseline and $20 \pm 4 \mathrm{hrs}$, between the IP and the respective control product. The results of the two studies were independent and not compared with each other. SPSS v. 6.1.3. (study 1) and v.3.4.3 (study 2) were used to perform the statistical analysis; $P<0.05$ was considered statistically significant.

\section{Ethical consideration}

All subjects provided signed informed consent. The studies were performed taking into account the principles of Good Clinical Practice (E6: CPMP/ICH/135/95) and the Declaration of Helsinki 1964 and its subsequent amendments. Due to the nature of the IP being cosmetic rather than medicinal, ethics committee approval was not required.

\section{Results}

The details of the study subjects are presented in Table 2. The distribution by phototype was, for study 1: $0 \%$ Fitzpatrick type I, 32\% type II, 66\% type III, 3\% type IV; for study $2: 7 \%$ type I, $41 \%$ type II, $52 \%$ type III.

\section{UV doses}

In study 1 , the maximum UV index was 5.9, and the mean $( \pm \mathrm{SD})$ total cumulative dose $(6 \mathrm{hrs})$ of erythemal UVB radiation was $200.3 \pm 14.8 \mathrm{~mJ} / \mathrm{cm}^{2}$. Sunscreens (IP and control) were applied a mean 3.2 times (min 2-max 5) during the 6-hr solar exposure period. In study 2 , the maximum UV index during study hours was 8.5, and the mean total

Table 2 Study subject characteristics

\begin{tabular}{|c|c|c|}
\hline & Study I & Study 2 \\
\hline No. participants & 38 & 29 \\
\hline Withdrew ${ }^{\mathrm{a}}$ & 0 & 1 \\
\hline Excluded ${ }^{b}$ & 0 & I \\
\hline Included in analysis & 38 & 27 \\
\hline Age, mean (min-max) & $43(2 I-59)$ & $39(18-55)$ \\
\hline \multicolumn{3}{|l|}{ Sex } \\
\hline Female & 30 (79\%) & 17 (63\%) \\
\hline Male & $8(21 \%)$ & $10(37 \%)$ \\
\hline \multicolumn{3}{|l|}{ Fitzpatrick phototype } \\
\hline 1 & $0(0 \%)$ & $2(7 \%)$ \\
\hline II & $12(32 \%)$ & II (4I\%) \\
\hline III & $25(66 \%)$ & 14 (52\%) \\
\hline IV & I (3\%) & NA \\
\hline
\end{tabular}

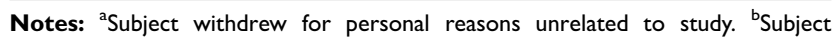
excluded for protocol noncompliance.

Abbreviation: NA, not applicable (subjects with skin phototype IV were not included in this study). cumulative dose ( $4 \mathrm{hrs}$ ) of erythemal UVB radiation was $164.9 \pm 15.8 \mathrm{~mJ} / \mathrm{cm}^{2}$. Sunscreens were applied a mean 1.7 times (min 1-max 2) during the 4-hr exposure period.

\section{Erythema}

In both studies, in skin treated with the IP, there was no statistically significant difference in erythema score from baseline to $20 \pm 4 \mathrm{hrs}$ after exposure (Tables 3 and 4).

In study 1 , the erythema score at $20 \pm 4$ hrs was not significantly different from baseline for the IP (mean erythema score increase of $6 \%, P=0.66$ ) but was significantly higher for the SPF15 product (mean erythema score increase of $16 \%$, $P<0.01$ ). Only 3 subjects had an increase in the erythema score (of 1 point) for the area covered with the IP, vs 9 subjects for the area covered with the SPF15 (8 with an increase of 1 point and 1 with an increase of 2 points) (Table 5).

In study 2 , there was no statistically significant difference in erythema score at $20 \pm 4$ hrs between the IP and the control SPF50 $+(P=0.45)$.

A post-hoc analysis (Wilcoxon test) by Fitzpatrick skin type subgroups (type II vs type III in study 1 and type I+II vs type III in study 2) revealed no statistically significant differences between groups for changes at $24 \mathrm{hrs}$.

\section{Tolerability}

In study 1 , no skin or eye reactions were reported. In study 2 (vs SPF50+), no skin reactions occurred. Two subjects reported ocular itching with both the IP and the control sunscreen (bilateral itch), and 2 subjects had itching with the control sunscreen but not the IP (unilateral).

\section{Discussion}

These two studies show that, with the recommended application quantity ( $2 \mathrm{mg} / \mathrm{cm}^{2}$ ), following $4-6 \mathrm{hrs}$ of outdoor sun exposure in a Mediterranean location in summer, the investigational water-based SPF50+ sunscreen product prevented solar erythema - indicative of inflammation in individuals with Fitzpatrick phototypes I-IV, which is of clinical interest regarding long-term skin health. The IP was superior to SPF15 and had a comparable level of photoprotection to an existing SPF50+, confirming the product provided a very high level of sun protection.

It was somewhat surprising to observe that in the SPF15 control group, there was a statistically significant increase in erythema $(+16 \%)$, which could suggest that SPF15 is insufficient under such circumstances of summer weather and in subjects with a majority (66\%) Fitzpatrick phototype III. Assessing the minimum SPF required to 
Table 3 Clinical erythema scoring results from study I (vs SPFI5)

\begin{tabular}{|c|c|c|c|c|}
\hline \multicolumn{5}{|c|}{ Clinical score ${ }^{a}$ mean $\pm S D$} \\
\hline & Baseline & $\mathbf{T} 24^{\mathrm{b}}$ & Mean \% change & \\
\hline IP & $3.05 \pm 1.43$ & $3.08 \pm 1.30$ & $\uparrow 6 \% \pm 24 \%$ & $P=0.65$ vs baseline ${ }^{c}$ \\
\hline \multirow[t]{2}{*}{ Reference SPFI5 } & $2.89 \pm 1.37$ & $3.16 \pm 1.26$ & $\uparrow 16 \% \pm 32 \%$ & $P<0.0$ I vs baseline ${ }^{c}$ \\
\hline & & & $P=0.02$ vs reference $S P F I 5^{c}$ & \\
\hline
\end{tabular}

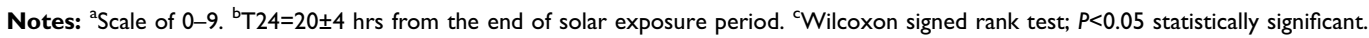

Abbreviations: IP, investigational product; SPF, sun protection factor.

Table 4 Clinical erythema scoring results from study 2 (vs SPF50+)

\begin{tabular}{|c|c|c|c|c|}
\hline \multicolumn{5}{|c|}{ Clinical score ${ }^{\mathrm{a}}$ mean \pm SD } \\
\hline & Baseline & $\mathbf{T} 24^{\mathrm{b}}$ & Mean \% change & \\
\hline IP & $0.3 \pm 0.5$ & $0.5 \pm 0.6$ & $\uparrow 5 \% \pm 10 \%$ & $P=0.06$ vs baseline ${ }^{c}$ \\
\hline \multirow[t]{2}{*}{ Reference SPF50+ } & $0.4 \pm 0.5$ & $0.7 \pm 0.6$ & $\uparrow 7 \% \pm \mid 4 \%$ & NP \\
\hline & & & $P=0.14$ vs reference $S P F 50+{ }^{c}$ & \\
\hline
\end{tabular}

Notes: ${ }^{\mathrm{a}} \mathrm{S}$ cale of $0-4{ }^{\mathrm{b}} \mathrm{T} 24=20 \pm 4 \mathrm{hrs}$ from the end of solar exposure period. 'Wilcoxon signed rank test; $P<0.05$ statistically significant.

Abbreviations: IP, investigational product; NP, not performed; SPF, sun protection factor.

Table 5 Increases in erythema scores at $24 \mathrm{hrs}$

\begin{tabular}{|l|l|l|l|l|}
\hline Study & Product & No increase & Increase by I point & Increase by $\geq 2$ points \\
\hline Study I (N=38) & IP & 35 & 3 & 0 \\
& SPFI5 & 29 & 8 & I \\
\hline Study 2 (N=27) & IP & 22 & 5 & 0 \\
& SPF50+ & 20 & 6 & 1 \\
\hline
\end{tabular}

Abbreviations: IP, investigational product; SPF, sun protection factor.

prevent erythema was not the primary endpoint of this study, but it is interesting to reflect on this finding within the context of the recommendations from established associations: while some recommend a minimum SPF of $15,{ }^{26}$ others suggest SPF30. ${ }^{27,28}$ Indeed, dermatologists may simply recommend "the highest possible protection" to their patients. ${ }^{7}$ Our findings point toward the latter options being more appropriate, although establishing such a recommendation was not our objective. Nonetheless, any reduction in erythema is viewed as beneficial due to its association with inflammatory processes.

The uniqueness of this study lies in its design. Being an outdoor study, it allowed us to include the full spectrum of solar radiation, including visible and infrared light. ${ }^{2}$ In addition, the split-face design minimized variability and allowed us to position the product with reference to existing sun protection products, while maintaining scientific standards that ensured a fair comparison of the tested products, and ensuring application in line with recommended methods of use. Although study 2 (vs SPF50+) was carried out in July when the UV radiation is higher than that in September, shorter exposure periods outside of solar noon resulted in smaller doses.

While most studies testing sunscreen efficacy are conducted indoors, there are very few studies comparing sunscreens in real-life conditions of solar radiation exposure. A recent study by Williams et $\mathrm{al}^{24}$ assessed in 199 healthy men and women in a single-center randomized controlled split-face double-blind study the sunburn protection provided by an SPF100+ vs SPF50+ sunscreen in actual use conditions. They concluded that the SPF $100+$ sunscreen was significantly more effective in protecting against sunburn than SPF $50+.^{24}$ Those results support the idea that higher SPFs may provide meaningfully improved photoprotection in real conditions of use by compensating for users' under-application (in the study, subjects applied around $1 \mathrm{mg} / \mathrm{cm}^{2}$, in contrast to the 
recommended $2 \mathrm{mg} / \mathrm{cm}^{2}$ ). Our study, in comparison, had some not dissimilar findings in that the investigational SPF50+ product was superior in efficacy to the SPF15 control product; however, in contrast to the previous study, this difference cannot be attributed to suboptimal use, since both products were applied by a trained technician at $2 \mathrm{mg} / \mathrm{cm}^{2}$ and reapplied at approximately 2 hourly intervals (a mean 1.7 times in the 4hr study and 3.2 times in the 6-hr study).

The studies reported here demonstrate that the product protects against erythema, which is known to be induced principally by UVB and UVA-II radiation. ${ }^{2}$ Although our study took place outdoors, and therefore included the full naturally occurring range of light, it did not specifically assess UVA-induced damage; however, the IP has an in vivo UVA protection factor of 20.3.

One limitation of the study design is that the two clinical assessments used different scales (0-9 and 0-4, respectively). Use of the same scale in both studies would have allowed a clearer direct comparison of results. This difference was due to the two studies being conducted by two independent contract research organizations, and the fact that there is no established standard scale for quantification of solar-induced erythema. However, a previous study ${ }^{23}$ concluded that such visual methods, namely, a 10point scale, were "sensitive, reliable and reproducible within a testing institution". It is interesting to note that, while a 10-point scale may be described as more sensitive than a 5-point scale, and did indeed pick up a change in SPF15-treated skin, its use did not result in finding a significant change in IP-treated skin in the same study.

The interpretation of the results can be applied to similar settings, that is, those permitting a variety of quiet outdoor activities. Further studies are planned to assess the product's efficacy under extreme UV conditions, and the product has previously undergone testing in wetskin, with a result similar to that in the standard SPF testing (unpublished data).

The results of these outdoor studies also demonstrate that the study design used was able to discriminate between an SPF15 sunscreen and the investigational SPF50+ sunscreen in terms of clinical photoprotective capacity.

This water-based broad-spectrum SPF50+ sunscreen has been demonstrated to provide very high protection against solar-induced erythema. Naturally, this does not abrogate the established sun-safe advice to continue to seek shade and use protective clothing; rather, this product can powerfully bolster such approaches, and along with ongoing user education, ${ }^{29}$ optimize solar skin protection. ${ }^{30,31}$ As sunscreen is often the main preventive strategy employed, ${ }^{29}$ it is essential that the product used be as highly effective as possible and that the texture of the formulation encourage adequate and frequent reapplication of the product. As Wang et $\mathrm{al}^{32}$ concluded, the best sunscreen is the one that is actually used.

\section{Conclusion}

In outdoor conditions in Mediterranean summer sun, this water-based broad-spectrum SPF50+ sun protection product had a very high photoprotective effect: a level comparable to an existing SPF50+ sunscreen and superior to the SPF15 reference sunscreen, even in phototype III and IV skin.

\section{Acknowledgments}

A medical writer (J. Marshall) assisted in drafting the manuscript. The authors would like to acknowledge the Spanish Meteorological Service for the provision of the radiation measurements.

\section{Disclosure}

CG and CT are employees of ISDIN, who manufactured the product and sponsored the study. The authors report no other conflicts of interest in this work.

\section{References}

1. Lautenschlager S, Wulf HC, Pittelkow MR. Photoprotection. Lancet. 2007;370(9586):528-537. doi:10.1016/S0140-6736(07)60638-2

2. Sklar LR, Almutawa F, Lim HW, Hamzavi I. Effects of ultraviolet radiation, visible light, and infrared radiation on erythema and pigmentation: a review. Photochem Photobiol Sci. 2013;12(1):54-64. doi:10.1039/c2pp25152c

3. British Association of Dermatologists. Past Campaign Activities. Available from: http://www.bad.org.uk/for-the-public/sun-awarenesscampaign/past-campaigns. Accessed January 14, 2019.

4. Centers for Disease Control and Prevention (CDC). Sunburn and sun protective behaviors among adults aged 18-29 years-United States, 2000-2010. MMWR Morb Mortal Wkly Rep. 2012;61(18):317-322.

5. Gilchrest BA, Eller MS, Geller AC, Yaar M. The pathogenesis of melanoma induced by ultraviolet radiation. $N$ Engl J Med. 1999;340 (17):1341-1348. doi:10.1056/NEJM199904293401707

6. Dennis LK, Vanbeek MJ, Beane Freeman LE, Smith BJ, Dawson DV, Coughlin JA. Sunburns and risk of cutaneous melanoma: does age matter? A comprehensive meta-analysis. Ann Epidemiol. 2008;18 (8):614-627. doi:10.1016/j.annepidem.2008.04.006

7. Farberg AS, Glazer AM, Rigel AC, White R, Rigel DS. Dermatologists' perceptions, recommendations, and use of sunscreen. JAMA Dermatol. 2017;153(1):99-101. doi:10.1001/jamadermatol.2016.3698

8. Wang SQ, Balagula Y, Osterwalder U. Photoprotection: a review of the current and future technologies. Dermatol Ther. 2010;23(1):31-47. doi:10.1111/j.1529-8019.2009.01289.x

9. Faurschou A, Wulf HC. The relation between sun protection factor and amount of sunscreen applied in vivo. $\mathrm{Br} J$ Dermatol. 2007;156 (4):716-719. doi:10.1111/j.1365-2133.2006.07684.x 
10. Jovanovic Z, Schornstein T, Sutor A, Neufang G, Hagens R. Conventional sunscreen application does not lead to sufficient body coverage. Int J Cosmet Sci. 2017;39(5):550-555. doi:10.1111/ics.12413

11. Solky B, Phillips P, Christenson L, Weaver A, Roenigk R, Otley C. Patient preferences for facial sunscreens: a split-face, randomized, blinded trial. J Am Acad Dermatol. 2007;57(1):67-72. doi:10.1016/j.jaad.2007.04.003

12. Xu S, Kwa M, Agarwal A, Rademaker A, Kundu R. Sunscreen product performance and other determinants of consumer preferences. JAMA Dermatol. 2016;152(8):920-927. doi:10.1001/jamadermatol.2016.2344

13. International Organization for Standardization. Standard 2444:2010. Cosmetics - Sun protection test methods - In vivo determination of the sun protection factor (SPF). Available from https://www.iso.org/ standard/46523.html. Accessed January 14, 2019.

14. Schalka S, Reis VM. Sun protection factor: meaning and controversies. An Bras Dermatol. 2011;86(3):507-515. [Article in English, Portuguese].

15. Osterwalder U, Schütz R, Vollhardt J. SPF assessment revisited status and outlook. Sofw J. 2018;144:38-42.

16. Food and Drug Administration. Labeling and Effectiveness Testing: Sunscreen Drug Products for Over-The-Counter Human Use Small Entity Compliance Guide. December 2012. Available from: https://www.fda.gov/drugs/guidancecomplianceregulatoryinforma tion/guidances/ucm330694.htm. Accessed January 14, 2019.

17. Pelizzo M, Zattra E, Nicolosi P, Peserico A, Garoli D, Alaibac M. In vitro evaluation of sunscreens: an update for the clinicians. ISRN Dermatol. 2012;2012:352135.

18. Calixto LS, Maia Campos PMBG, Savary G, Picard C. Interactions between UV filters and active substances in emulsion: effect on microstructure, physicochemical and in-vivo properties. Int J Pharm. 2018;553(1-2):220-228. doi:10.1016/j.ijpharm.2018.10.027

19. Binks BP, Brown J, Fletcher PD, et al. Evaporation of sunscreen films: how the UV protection properties change. ACS Appl Mater Interfaces. 2016;8(21):13270-13281. doi:10.1021/acsami.6b02696

20. Commission Internationale de l'Eclairage (CIE). Erythema Reference Action Spectrum and Standard Erythema Dose, CIE S007E-1998. Vienna (Austria): CIE Central Bureau; 1998.

21. World Health Organization, World Meteorological Organization, United Nations Environment Programme \& International Commission on NonIonizing Radiation Protection. Global Solar UV Index: A Practical Guide. Geneva: World Health Organization; 2002. Available from: http://www. who.int/iris/handle/10665/42459.Accessed January 14, 2019.
22. Bech J, Sola Y, Ossó A, Lorente J. Analysis of 14 years of broadband ground-based solar UV index observations in Barcelona. Int J Climatol. 2015;35(1):45-56. doi:10.1002/joc.3961

23. Basketter D, Reynolds F, Rowson M, Talbot C, Whittle E. Visual assessment of human skin irritation: a sensitive and reproducible tool. Contact Dermatitis. 1997;37(5):218-220.

24. Williams JD, Maitra P, Atillasoy E, Wu MM, Farberg AS, Rigel DS. SPF $100+$ sunscreen is more protective against sunburn than SPF 50+ in actual use: results of a randomized, double-blind, split-face, natural sunlight exposure clinical trial. J Am Acad Dermatol. 2018;78 (5):902-910.e2. doi:10.1016/j.jaad.2017.12.062

25. Ou-Yang H, Jiang LI, Meyer K, Wang SQ, Farberg AS, Rigel DS. Sun protection by beach umbrella vs sunscreen with a high sun protection factor: a randomized clinical trial. JAMA Dermatol. 2017;153(3):304-308. doi:10.1001/jamadermatol.2016.4922

26. Center for Disease Control and Prevention. Available from: https:// www.cdc.gov/cancer/skin/basic_info/sun-safety.htm. Accessed January 14, 2019.

27. British Association of Dermatologists. Sunscreen and sun safety factsheet. 2013. Available from: http://www.bad.org.uk/shared/get-file. ashx?id=3917\&itemtype=document. Accessed January 14, 2019.

28. American Cancer Society. Choose the right sunscreen. 2018. Available from: https://www.cancer.org/latest-news/choose-the-rightsunscreen.html. Accessed January 14, 2019.

29. Linos E, Keiser E, Fu T, Colditz G, Chen S, Tang JY. Hat, shade, long sleeves, or sunscreen? Rethinking US sun protection messages based on their relative effectiveness. Cancer Causes Control. 2011;22 (7):1067-1071. doi:10.1007/s10552-011-9780-1

30. Green A, Williams G. Point: sunscreen use is a safe and effective approach to skin cancer prevention. Cancer Epidemiol Biomarkers Prev. 2007;16(10):1921-1922. doi:10.1158/1055-9965.EPI-07-0477

31. Glanz K, Buller DB, Saraiya M. Reducing ultraviolet radiation exposure among outdoor workers: state of the evidence and recommendations. Environ Health. 2007;6:22. doi:10.1186/1476069X-6-22

32. Wang SQ, Virmani P, Lim HW. Consumer acceptability and compliance: the next frontier in sunscreen innovation. Photodermatol Photoimmunol Photomed. 2016;32(1):55-56. doi:10.1111/phpp.12211
Clinical, Cosmetic and Investigational Dermatology

\section{Publish your work in this journal}

Clinical, Cosmetic and Investigational Dermatology is an international, peer-reviewed, open access, online journal that focuses on the latest clinical and experimental research in all aspects of skin disease and cosmetic interventions. This journal is indexed on CAS.
The manuscript management system is completely online and includes a very quick and fair peer-review system, which is all easy to use. Visit http://www.dovepress.com/testimonials.php to read real quotes from published authors. 